\title{
Ultra-Thin $\mathrm{ZnFe}_{2} \mathrm{O}_{4}$ Nanosheets-Decorated $\mathrm{ZnO}$ Hollow Nanofibers for High Sensitive Acetone Sensor
}

\author{
Xiaowei Li ${ }^{1}$, Changlu Shao ${ }^{1}$, Xinghua $L^{1}{ }^{1}$, Geyu Lü ${ }^{2}$ Yichun Liu ${ }^{1}$ \\ ${ }^{1}$ Center for Advanced Optoelectronic Functional Materials Research, and Key Laboratory of UV- \\ Emitting Materials and Technology (Northeast Normal University), Ministry of Education, 5268 Renmin \\ Street, Changchun, 130024, People's Republic of China \\ ${ }^{2}$ State Key Laboratory on Integrated Optoelectronics, College of Electronic Science and Engineering, \\ Jilin University, Changchun, 130012, People's Republic of China \\ lixw447@nenu.edu.cn
}

\begin{abstract}
:
Heterostructures may exhibit not only a combination of properties from the individual component but also enhanced properties arising from the synergistic effects between the components[1]. In this study, a multi-step strategy for constructing $\mathrm{ZnO} / \mathrm{ZnFe} \mathrm{O}_{4}$ hollow nanofibers with double-shell architectures was presented. The preparation of $\mathrm{ZnO}$ hollow nanofiber included the first preparation of PVP nanofiber through electrospinning as an hard template and then growth of ultrathin $\mathrm{ZnO}$ layer through atomic layer deposition (ALD) method with subsequent annealing process. Subsequently, the growth of the ultrathin $\mathrm{ZnFe}_{2} \mathrm{O}_{4}$ nanosheets (ca.10 nm) on the $\mathrm{ZnO}$ outer surface was carried out at room temperature via solution reactions in order to generate heterostructures and large surface area. When evaluated as a novel sensing material for acetone $\left(\mathrm{C}_{3} \mathrm{H}_{6} \mathrm{O}\right)$ detection, the resultant tube-like $\mathrm{ZnO} / \mathrm{ZnFe}_{2} \mathrm{O}_{4}$ heterostructures exhibited obviously enhanced sensing response, lower operating temperature as well as faster response/recover speed during the dynamic measurement compared to the bare $\mathrm{ZnO}$ hollow nanofiber, which endow these $\mathrm{ZnO} / \mathrm{ZnFe}_{2} \mathrm{O}_{4}$ heterostructures with a potential application in gas sensing.
\end{abstract}

Key words: $\mathrm{ZnO} / \mathrm{ZnFe}_{2} \mathrm{O}_{4}$, heterostructure, gas sensor, hollow nanofiber, ALD
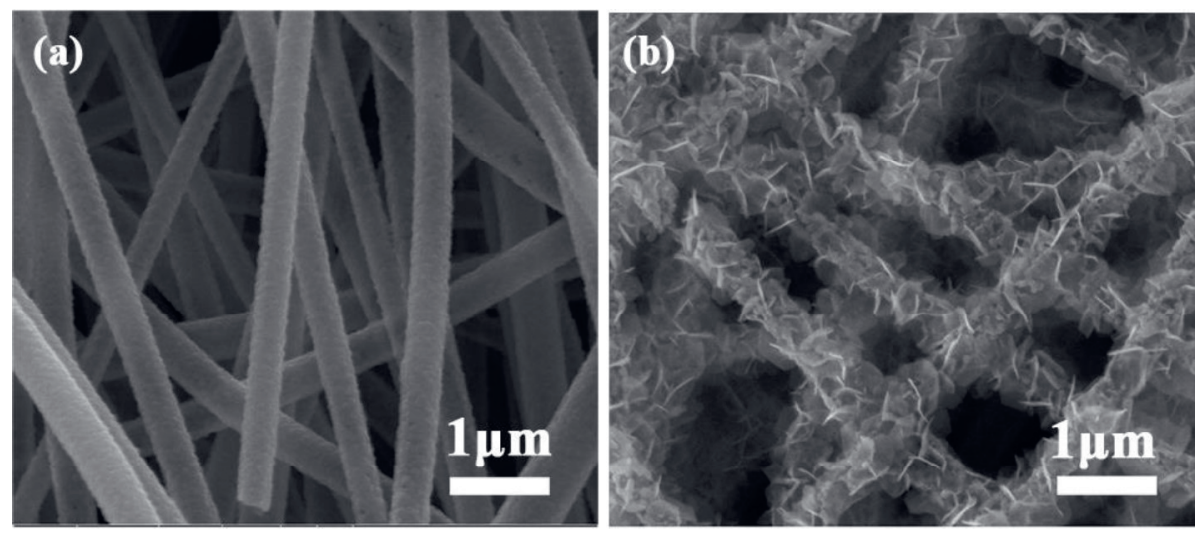

Fig. 1. SEM images of (a) bare $\mathrm{ZnO}$ and (b) $\mathrm{ZnO} / \mathrm{ZnFe}{ }_{2} \mathrm{O}_{4}$ heterostructure.

\section{References}

[1]D. R. Miller, S. A. Akbar, P. A. Morris, Nanoscale Metal Oxide-Based Heterojunctions for Gas Sensing: A Review, Sensors and Actuators B: Chemical 204, 250-272 (2014); doi: 10.1016/j.snb.2014.07.074 